\title{
Influence of Concrete Compressive Strength on Transfer Length in Pretensioned Concrete Members Using 3D Nonlinear FEM Analysis
}

\author{
Zaher Alkurdi ${ }^{1}$ \\ ${ }^{1}$ Budapest University of Technology and Economics \\ Müegyetem rkp. 3, 1111, Budapest, Hungary \\ zaher.alkurdi@epito.bme.hu
}

\section{Extended Abstract}

Reinforced concrete is one of the most common structural materials in civil engineering [1]. Since the 1950s, prestressed concrete has been widely used [2]. In pretensioned prestressed concrete technology, the prefabrication contributes to a quicker construction process, high-quality fabrication, optimal usage of properties of applied materials, and solutions to the limitations connected with environmental issues [3].

Without a bond, the concrete members would not be pretensioned. The anchorage and development of prestressing force depend exclusively on the bond after the release of strands [4]. The bond may be categorized as transfer or flexural. A transfer bond occurs at the release of the prestressing strand through the transfer of the prestress force from the strand to the concrete in the end zone. The transfer length is the distance from the end of the concrete to the point where the strand stress reaches a constant level (the effective prestress after losses). Its value depends on parameters such as prestressing level, the strength of concrete at tension release, the diameter of the strand, type of release (gradual or sudden), surface condition of the strand (clean, oiled, rusted), confining reinforcement around the strand, the time elapsed after the transfer, the position of the strand in the member (top or bottom), type of concrete curing, and other factors [5].

The transfer lengths of the prestressing strands are estimated experimentally or from empirical formulae given in various design codes $[6,7,8]$. These formulae provide varied predictions in transfer length. The literature confirms that concrete compressive strength strongly affects the transfer length. In addition, some design codes, like ACI 318-14 [6] and AASHTO LRFD [7], do not take compressive strength into account, as only strand parameters are considered. These formulae overestimate transfer length when concrete quality is good. The transfer length is an essential parameter in the shear design and determination of allowable stresses. Inaccurate estimation of this length can affect the shear capacity of a member and result in serviceability issues that occur in the end zones at strand release $[8,9]$. Therefore, accurate transfer length estimation is needed, which can be accomplished by incorporating concrete compressive strength in the transfer length equation.

Numerical modelling has made considerable progress in this area. Furthermore, numerical modelling is being implemented in design because experiments can be challenging, unwelcome, costly, or time-consuming. In addition, model predictions closely align with experimental testing.

This article aims to study the effects of concrete compressive strength on the transfer length in pretensioned concrete members with numerical modelling. The first step is to validate a pretensioned concrete beam based on previous results in the literature. The second step is to model roughly 50 pretensioned beams of various concrete types and examine the transfer lengths. The concrete types will have compressive strengths classified as normal, high, very high, and ultra-high, ranging from 20 to $155 \mathrm{MPa}$, respectively. Low-relaxation grade 1862 strand $\left(f_{p u}=1862 \mathrm{MPa}\right)$ will be used with a pretensioned magnitude is up to $0.8 f_{p u}$. This evaluation will yield an equation that defines the transfer length using power regression. The results will be compared with those predicted by ACI and AASHTO LRFD. 


\section{References}

[1] M. Abed, "Numerical Evaluation of Bond Behavior of Ribbed Steel Bars or Seven-wire Strands Embedded in Lightweight Concrete," Periodica Polytechnica Civil Engineering, vol. 65, no. 2, pp. 385-396, 2021.

[2] D. P. Billington, "Historical perspective on prestressed concrete," PCI Journal, vol. 21, no. 5, pp. 48-71, 1976.

[3] B. H. Oh and E. S. Kim, "Realistic Evaluation of Transfer Lengths in Pretensioned Prestressed Concrete Members," ACI Structural Journal, vol. 97, pp. 821-830, 2000.

[4] X. Jiang, "Bond Performance of High-Capacity Strands in High Strength Concrete," Ph.D. dissertation, Dept. Civ. Eng., Tennessee Univ., Knoxville, TN.

[5] G. L. Balazs, "Transfer control of prestressing strands," PCI Journal, vol. 37, no. 6, pp. 60-71, 1992.

[6] ACI-318-14, Building code requirements for structural concrete and commentary. Farmington Hills, MI: American Concrete Institute, 2014.

[7] AASHTO LRFD bridge design specifications, American Association of State Highway and Transportation Officials, Washington, DC, 2012.

[8] N. M. C. fib special activity group, L. Taerwe, and S. Matthys, fib Model Code for Concrete Structures 2010. Berlin, Germany: Ernst \& Sohn, Wiley, 2013.

[9] H.Yu and D. Jeong, "Finite element bond modeling for indented wires in pretensioned concrete crossties," presented at the Proceedings of the Joint Rail Conference, Columbia, SC, 2016, vol. 49675, pp. 1-10. 